are much lower than those of oral corticotherapy. We recommend that large, controlled studies compare this treatment to oral corticosteroids in cases of allergic bronchopulmonary aspergillosis, both in cystic fibrosis and asthmatic patients.

\section{Y. Laoudi, J-B. Paolini, A. Grimfed and J. Just}

Dept of Multidisciplinary Paediatrics, Centre of Asthma and Allergies of the Child, Public Assistance of Paris' Hospitals, Hospital Group Trousseau/La Roche Guyon, Pierre and Marie Curie Univeristy, Paris, France.

\section{STATEMENT OF INTEREST}

None declared.

\section{REFERENCES}

1 Stevens DA, Moss RB, Kurup VP, et al. Allergic bronchopulmonary aspergillosis in cystic fibrosis - state of the art: Cystic Fibrosis Foundation Consensus Conference. Clin Infect Dis 2003; 37: Suppl. 3, S225-S264.
2 Skowronski E, Fitzgerald DA. Life-threatening allergic bronchopulmonary aspergillosis in a well child with cystic fibrosis. Med J Aust 2005; 182: 482-483.

3 Skov M, Main KM, Sillesen IB, Muller J, Koch C, Lanng S. Iatrogenic adrenal insufficiency as a side-effect of combined treatment of itraconazole and budesonide. Eur Respir J 2002; 20: 127-133.

4 Leon EE, Craig TJ. Antifungals in the treatment of allergic bronchopulmonary aspergillosis. Ann All Ast Immunol 1999; 82: 511-517.

5 Elphick H, Southern K. Antifungal therapies for allergic bronchopulmonary aspergillosis in people with cystic fibrosis. Cochrane Database Syst Rev 2000; 4: CD002204.

6 Seaton A, Seaton RA, Wightman AJ. Management of allergic bronchopulmonary aspergillosis without maintenance oral corticosteroids: a fifteen-year follow-up. QJM 1994; 87: 529-537.

7 British Thoracic Association, Inhaled beclomethasone diproprionate in allergic bronchopulmonary aspergillosis. $\mathrm{Br} \mathrm{J} \mathrm{Dis}$ Chest 1979; 73: 349-356.

\title{
Elevated levels of exhaled nitric oxide in recurrent tonsillitis
}

\section{To the Editors:}

Nitric oxide (NO) is a free radical generated from L-arginine through the NO synthases (NOS). This molecule is produced within the respiratory tract and plays an important role in airway pathophysiology, exerting both beneficial and nonbeneficial effects $[1,2]$.

Because various pro-inflammatory mediators and lipopolysaccharides are capable of inciting inducible NOS (iNOS) expression [2], different airway inflammatory diseases are associated with increased NO release, which is detectable in exhaled gas, including asthma [3], bronchiectasis [4], allergic rhinitis [5] and upper respiratory tract infections [6]. However, not all sources of the elevated exhaled NO (eNO) have been identified as yet. Interestingly, it has been suggested that iNOS expression and formation of peroxynitrite may play an important role in the pathogenesis of recurrent tonsillitis [7]. To investigate whether recurrent tonsillitis is associated with increased levels of eNO, we measured oral eNO levels in adult patients with a history of frequent tonsillitis episodes.

The study group consisted of 32 nonatopic, nonsmoking patients with recurrent tonsillitis, scheduled for tonsillectomy (18 females; median (range) age $28(18-50)$ yrs). All patients had a history of frequent episodes of tonsillitis over many years. All patients had received antibiotic treatment $>1$ month prior to surgery. Specific exclusion criteria were diseases that may affect eNO concentration, including asthma, rhinitis and sinusitis. Routine histological examination of tonsillectomy was performed for each of the cases.

A total of 35 nonatopic, nonsmoking healthy subjects (20 females; age 30 (18-49) yrs) were included in the control group. Oral eNO levels were measured in triplicate using the Niox Mino ${ }^{\circledR}$ analyser (Aerocrine AB, Solna, Sweden). The level of NO is expressed in ppb.

Statistical analysis was performed using the Mann-Whitney U-test. A p-value $<0.05$ was considered significant.

eNO levels were significantly higher in patients with recurrent tonsillitis $(21.0(6.0-50.0) \mathrm{ppb})$ than in normal controls (17.0 (5.0-26.0) ppb; $\mathrm{p}<0.05$; fig. 1). This suggests that recurrent tonsillitis may increase the level of NO in exhaled air. eNO can be a sensitive marker of inflammation in the respiratory tract but is not specific for asthma, as increased levels of oral eNO have been observed in other diseases, including infections of the upper respiratory tract [6]. However, NO levels did not differ between healthy subjects and common cold patients, and were significantly lower in patients suffering from chronic sinusitis [8] as well as from acute sinusitis [9].

The present study was the first to show that, to the best of our knowledge, oral exhaled nitric oxide can be elevated in patients with recurrent tonsillitis, probably as a result of the 


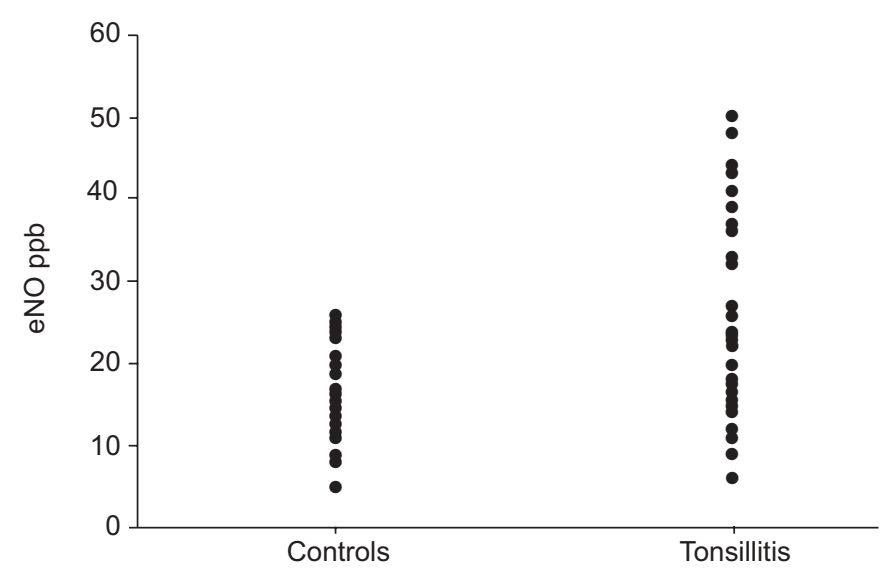

FIGURE 1. Exhaled nitric oxide (eNO) in patients suffering from recurrent tonsillitis and healthy subjects.

increased production of nitric oxide formed by inducible nitric oxide synthase in tonsillar tissue resulting from inflammation. The potential inflammatory role of the L-arginine-nitric oxide pathway in the pathogenesis of chronic/recurrent tonsillitis and chronic adenotonsillar hypertrophy has been suggested [7, 10]. An extended study to consider patients after the therapy (tonsillectomy) should be the subject of future investigations.

\section{A. Kasperska-Zajac*, Z. Brzoza*, E. Czecior", B. Rogala*,} A. Polok ${ }^{\#}$ and G. Namyslowski ${ }^{\#}$

${ }^{*}$ Clinical Dept of Internal Diseases, Allergology and Clinical Immunology in Zabrze, and "Clinical Dept of Otolaryngology in Zabrze, Medical University of Silesia, Katowice, Poland.

\section{STATEMENT OF INTEREST}

None declared.

\section{REFERENCES}

1 Moncada S, Palmer RM, Higgs EA. Nitric oxide: physiology, pathophysiology, and pharmacology. Pharmacol Rev 1991; 43: 109-142.

2 Nathan C, Shiloh MU. Reactive oxygen and nitrogen intermediates in the relationship between mammalian hosts and microbial pathogens. Proc Natl Acad Sci USA 2000; 97: 8841-8848.

3 Alving K, Weitzberg E, Lundberg JM. Increased amount of nitric oxide in exhaled air of asthmatics. Eur Respir J 1993; 6: 1368-1370.

4 Kharitonov SA, Wells AU, O'Connor BJ, et al. Elevated levels of exhaled nitric oxide in bronchiectasis. Am J Respir Crit Care Med 1995; 151: 1889-1893.

5 Martin U, Bryden K, Devoy M, Howarth P. Increased levels of exhaled nitric oxide during nasal and oral breathing in subjects with seasonal rhinitis. J Allergy Clin Immunol 1996; 97: 768-772.

6 Murphy AW, Platts-Mills TA, Lobo M, Hayden F. Respiratory nitric oxide levels in experimental human influenza. Chest 1998; 114: 452-456.

7 Wang HW, Su WF, Lin YS, Kang BH. Immunolocalization of inducible nitric oxide synthase and 3-nitrotyrosine in recurrently inflamed, human palatine tonsils. Eur Arch Otorhinolaryngol 2002; 259: 413B-418B.

8 Lindberg S, Cervin A, Runer T. Nitric oxide (NO) production in the upper airways is decreased in chronic sinusitis. Acta Otolaryngol 1997; 117: 113-117.

9 Baraldi E, Azzolin NM, Biban P, Zacchello F. Effect of antibiotic therapy on nasal nitric oxide concentration in children with acute sinusitis. Am J Respir Crit Care Med 1997; 155: 1680-1683.

10 Unal M, Cimen MY, Dogruer ZN, Cevik T. The potential inflammatory role of arginase and iNOS in children with chronic adenotonsillar hypertrophy. Int J Pediatr Otorhinolaryngol 2005; 69: 381B-385B. 